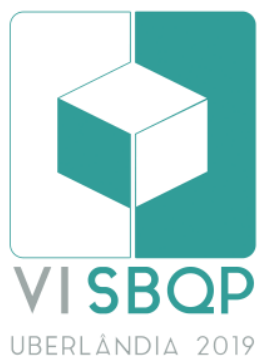

\title{
UMA IMAGEM DO MUSEU MILITAR DE DRESDEN: UM OLHAR PELO VIÉS DA GESTALT E DA GEOMETRIA
}

\author{
GNUTZMANN, Nathalia Teixeira \\ Universidade Federal de Pelotas, nathaliagnutzmann@hotmail.com \\ SILVA, Adriane Borda Almeida da \\ Universidade Federal de Pelotas, adribord@hotmail.com
}

\begin{abstract}
RESUMO
Este trabalho trata de observar como os conhecimentos advindos da geometria contribuem para a tradução de elementos da teoria da Gestalt. Utiliza-se de um estudo de caso, de análise de uma imagem do Museu Militar, da cidade de Dresden, na Alemanha. Esta imagem deriva de uma intervenção contemporânea em um edifício neoclássico, proposta por Daniel Libeskind, carregada de simbolismos explicitados pelo discurso do próprio arquiteto. Mediante um exercício de tradução de vocabulário entre Gestalt e geometria realiza-se uma leitura das relações formais estabelecidas entre a fachada original e os elementos da intervenção. Os resultados constituem-se como hipótese da intencionalidade do arquiteto em determinar posicionamentos precisos, de assimetria, de paralelismos e perpendicularidades, entre as formas da intervenção e as da fachada original, para provocar sensações visuais e remeter à carga simbólica da imagem referida.
\end{abstract}

Palavras-chave: Gestalt; Vocabulário; Geometria; Museu Militar de Dresden; Daniel Liberkind.

\begin{abstract}
This work tries to observe how the knowledge derived from geometry contributes to the translation of elements of the Gestalt theory. A case study, from an analysis of an image of the Military Museum, in the city of Dresden, Germany, is used. This image is derived from a contemporary intervention in a neoclassical building, proposed by Daniel Libeskind, loaded with symbolisms explained by the architect's own discourse. Through an exercise of vocabulary translation between Gestalt and geometry a reading of the formal relations established between the original facade and the elements of the intervention is realized. The results constitute a hypothesis of the architect's intention to determine precise positions, asymmetry, parallels and perpendicularities, between the forms of the intervention and those of the original facade, to provoke visual sensations and refer to the symbolic load of the image.
\end{abstract}

Keywords: Gestalt; Vocabulary; Geometry; Military Museum of Dresden; Daniel Liberkind

\section{INTRODUÇÃO}

Este estudo partiu de um interesse didático de promover uma postura de investigação em arquitetura, por meio da geometria gráfica, capaz de facilitar a compreensão do vocabulário empregado pela teoria da Gestalt em relação às estratégias de organização formal.

Utiliza-se do exercício de análise de um caso de projeto buscando assim estruturar hipóteses que associem elementos objetivos da geometria com a subjetividade atribuída a determinados efeitos de composição formal. Para tanto há que se partir da tentativa de compreender tais subjetividades, as quais derivam do processo de concepção do projeto, muitas vezes

GNUTZMANN, N. T.; SILVA, A. B. A. Uma Imagem do Museu Militar de Dresden: um olhar pelo viés da Gestalt e da Geometria. In: SIMPÓSIO BRASILEIRO DE QUALIDADE DO PROJETO NO AMBIENTE CONSTRUÍDO, 6., 2019, Uberlândia. Anais... Uberlândia: PPGAU/FAUeD/UFU, 2019. p. 1627-1635. DOl https://doi.org/10.14393/sbqp19147. 
expressadas no discurso do próprio arquiteto, e, logicamente condicionada pelo contexto do tempo e lugar onde o processo se desenvolve. Trata-se assim de compreender as estratégias de formalização de um conceito de projeto.

O conceito, como qualifica BRANDÃO (2000), tem a virtude de ser "fecundo" e não ser restritivo, a forma não deve ser uma expressão literal e nem o conceito deve vir para explicar a arquitetura. Não é uma tarefa que começa e termina e então o projeto é elaborado, mas ele deve evoluir simultâneo à práxis projetual e só alcançar o seu fim com a obra construída, então o conceito se transforma na percepção do observador e como ele interpreta a arquitetura.

Nessa perspectiva, observa-se como este conceito é construído na práxis projetual, na expectativa de que a obra de arquitetura provoque percepções e emoções de acordo com os propósitos do projetista. A psicologia, neste processo, pode auxiliar no entendimento cognitivo da linguagem arquitetônica. Tal relação se vislumbra no conjunto de estímulos que uma imagem proporciona, os quais atribuem significado ao objeto visualmente percebido. Para FLUSSER (2011), "Imagens oferecem aos seus receptores um espaço interpretativo: símbolos "conotativos".

Tal significação pode ser entendida através da Teoria da Gestalt, que advém da psicologia do começo do século XX. Segundo KÖHLER (1980), tal teoria apoia-se na fisiologia do sistema nervoso e expande a experiência sensorial. Trata o fenômeno como uma relação isomórfica entre o sujeito e o objeto, estabelecida a partir da "autodistribuição dinâmica" que organiza um "conjunto de estímulos" nos quais a "igualdade favorece o agrupamento".

O autor também explica que é a "significação de uma unidade concreta per se, que tem ou pode ter uma forma como uma de suas características", por isso, "no sentido de forma, já não é o centro da atenção da psicologia da Gestalt", pois "a organização sensorial é biologicamente muito mais importante do que as qualidades sensoriais particulares que aparecem nos campos visuais" KÖHLER (1980).

Nesse sentido, a arquitetura se constitui para além da técnica, causando sensações e trazendo em seus propósitos outras funções, incluindo a estética. ECO enfatiza tanto o atendimento à "função utilitária" quanto à "função simbólica". Para KÖHLER (1980) as experiências estão localizadas em um "espaço perceptivo" relacionando-se com os "fatos visuais", o autor segue indicando a fórmula psicológica da Gestalt "modelo de estímulo organização - reação aos produtos da organização".

Quanto ao modelo de estímulo, ele é composto pelo conjunto de estímulos, do qual a forma é parte integrante, mas não exclusiva. Nessa senda, forma, como Wong (1998) explica, é "qualquer entidade visual que compreenda todos os elementos visuais de formato, tamanho, cor e textura" e que pode ser "criada, construída e organizada em conjunto com outras formas". Nesse sentido Fonatti (1988) entende forma como processo, divisão, totalidade e variação, que pode acontecer a partir de uma estrutura como matriz formal, mas também associada ao movimento.

Observa-se assim a complexidade de introduzir o tema de compreensão de uma forma arquitetônica, tendo-se com este trabalho o propósito de abordar aspectos essencialmente geométricos como maneira de explicitar como que tal abordagem pode se estabelecer como infraestrutura para estudos mais 
avançados. Portanto, o interesse didático está dirigido aos estágios iniciais de formação em arquitetura, na expectativa de construção de um repertório geométrico que potencialize a percepção de estratégias intencionais de organização formal associadas a tipos de efeitos visuais subjetivos postulados pela psicologia, no caso abordados pela Teoria da Gestalt.

Por isso, o objetivo geral do trabalho é utilizar o conhecimento da geometria para análise de uma imagem de arquitetura e compreender como ele pode contribuir com o entendimento das leis da Gestalt. Para tal o termo forma terá abordagem geométrica e Gestalt abrangerá os efeitos visuais e suas significações. Com isto, trata-se de problematizar a compreensão desta teoria, buscando-se contribuir com a estruturação de exercícios de investigação sobre a possível explicitação de ações projetuais/geométricas intencionais associadas a determinadas sensações visuais.

\section{METODOLOGIA}

Esta pesquisa baseia-se na hermenêutica, pois propõe a interpretação "das expressões simbólicas das produções humanas, dos signos culturais" (SEVERINO, 2007). É de natureza básica, com abordagem qualitativa, o método é o estudo de caso e tem como objeto uma imagem do projeto para - Museu Militar da cidade de Dresden na Alemanha do arquiteto Daniel Libeskind.

Para isto, serão utilizados como procedimentos técnicos as pesquisas bibliográfica, documental e exploratória. A escolha da imagem analisada está sujeita as imagens divulgadas no site do arquiteto e que contemplam toda fachada principal a fim de interpretar intencionalidades. Analisa-se esta fachada como elemento cenográfico, apoiando-se em Flusser (2011), frente a sua avaliação de que é possível estabelecer "relações significativas" com os "elementos centrais" da obra, ao passo que "substituem eventos por cenas".

Tal análise terá caráter didático com foco na elaboração de hipóteses sobre as estratégias de transposição do conceito de projeto, no âmbito das sensações e necessidades subjetivas, à concepção formal e tem na geometria um auxílio para explicitar tal transposição e entender a aplicação da Gestalt como lógica projetual e como instrumento de análise de projeto.

\section{O CASO DE ESTUDO: UMA IMAGEM DO MUSEU MILITAR DE DRESDEN}

Dresden era a capital da Saxônia, considerada um centro cultural e a "Florença do Elba", rio que corta a cidade. Durante a Segunda Guerra Mundial a cidade recebeu inúmeros refugiados e feridos de guerra, atingindo seu ápice populacional no dia 12 de fevereiro, com a chegada "dos últimos trens oficiais do Leste transportando refugiados". Na tentativa de "desorganizar a evacuação de refugiados do Leste e de perturbar o movimento de tropas", entre os dias 13, 14 e 15 de fevereiro de 1945 a cidade recebeu um sincronizado e "maciço ataque aéreo" conhecido como "Tempestade de fogo" que destruiu a cidade e matou mais de "135.000" pessoas. (IRVING, 1963)

O "alvo inicial" do bombardeio era uma estação férrea localizada próxima ao rio Elba e foi organizado tendo como ponto de referência a curva em formato de "S" deste mesmo rio. De acordo com relatório encontrado por Irving (1963) 
14.467 edifícios, residenciais, comerciais e institucionais, foram totalmente "destruídos ou pesadamente danificados". Porém alguns não sofreram nenhum dano, como o objeto deste estudo, o Museu Militar.

O prédio original é uma construção de 1897 que chegou a abrigar o arsenal saxão, mas logo foi transformado no Museu da História Militar Alemã, ficando desocupado de 1989 até 2011 quando foi inaugurada a intervenção de Daniel Libeskind para reabrigar o Museu Militar.

Daniel Libeskind reúne em seu discurso elementos considerados facilitadores para a temática proposta neste estudo, principalmente quando se refere ao projeto desenvolvido para o Museu Militar de Dresden, na Alemanha. Em sua declaração à revista AU (2009), o arquiteto discursa sobre a correlação entre homem e arquitetura e afirma que "Arquitetura é arte pública. É linguagem, é comunicação".

Sobre a obra, o arquiteto explica seu anseio de mudar o paradigma "longe da celebração das guerras" e em texto fornecido pelo arquiteto ao Archdaily (2011), revela que a intenção projetual não era de preservar a fachada preexistente e sim de "criar uma interrupção ousada, um deslocamento fundamental, para penetrar no arsenal histórico e criar uma nova experiência". Na sequência é possível identificar um ponto importante para o conceito do projeto quando afirma que a arquitetura "envolverá o público na questão mais profunda de como a violência organizada e como a história militar e o destino da cidade estão interligados". Por fim, considera a obra como

[...] symbol of the resurrection of Dresden from its ashes. It is about the juxtaposition of tradition and innovation, of the new and the old. Dresden is a city that has been fundamentally altered; the events of the past are not just a footnote; they are central to the transformation of the city today.

Libeskind lista cinco premissas consideradas em sua intervenção: "Changing Perspective", prevendo para isto a justaposição de tradição e inovação, de antigas e novas interpretações da história militar alemã como sendo a pedra angular da nova abordagem; "Cultural History of Violence", destacando a necessidade do Museu de investigar mais profundamente a maneira como a cultura da violência se estabeleceu;

Reforçando assim que o tema central da arquitetura e do design de exposições deva ser a abordagem antropológica da natureza da violência, referindo-se aos tipos de expressões humanas que precipitam a guerra; "Museum as Forum", para que além de ser um local de exibição seja de discussão sobre temas atuais e históricos; "A New Museum District", tendo o propósito de que o novo museu transformasse o distrito de Albertstodt em um destino internacional, um centro cultural e um distrito de museus.

Alguns registros textuais por parte de críticos de arquitetura são encontrados. MOORE (2011), registra a percepção de que a premissa do projeto era "mostrar as causas humanas e os efeitos da guerra, em vez de ser um desfile de material". Entende-se que Moore quer destacar o cuidado com a seleção dos diferentes materiais, contrastantes com o edifício original, trazendo planos de vidro com transparência que cobrem parcialmente a fachada neoclássica e permitem descobrir a história que há por trás do vidro. 
Ainda, de acordo com o site do arquiteto Daniel Libeskind, na opinião de Hugh Pearman para Architectural Record (2012), o projeto é apropriado para sua função e atua como uma força para o bem. Esse entendimento vai ao encontro da ideia de que o museu deve promover a reflexão de como o ser humano lida com a cultura da violência e com o pós-guerra.

Andrea Kasiske em seu artigo para Deutsche Welle Brasil (2013), afirma que especialistas consideram a intervenção "altamente simbólica", o que vai ao encontro com a opinião de Ella Thorns para Archdaily (2017) quando comenta que "pontas afiadas e os duros ângulos [...] transmitem a dor e a crítica realidade da guerra". Para Alexander Georgi (DW, 2013), assessor de imprensa do Museu, o "observador deve estar em condições de formar sua própria opinião ao visitar o local".

O contexto, conceitos e informações sobre o Museu, já apresentados, instrumentalizam o observador para entender a linguagem da intervenção estruturada pelo Daniel Libeskind. Na sequência, realizou-se o exercício de análise da forma do projeto. Partiu-se da compreensão sobre a direção do traço do arquiteto para definir para onde aponta a forma de maior pregnância da intervenção. Observa-se no diagrama da direita da Figura 1 , sobre a planta baixa do térreo do Museu, a relação entre o eixo de simetria do edifício preexistente com o eixo de simetria da intervenção.

Sobre a imagem do mapa da cidade (à esquerda da figura), é possível compreender a intencionalidade do traço em função da relação com o entorno. Tal obra, que propõe uma conexão com a história militar alemã, tem como símbolo mais evidente dessa intenção o formato de uma seta, indicando assim um deslocamento do eixo do edifício para apontar para uma única direção.

Enquanto o eixo da preexistência se direciona ao centro histórico, o da intervenção sugere a mudança de perspectiva quando indica a direção da estação férrea da cidade, alvo inicial dos ataques a Dresden. Além disso, transpassa o único ponto de referência do referido ataque, a curva " $\mathrm{S}$ " do rio Elba.

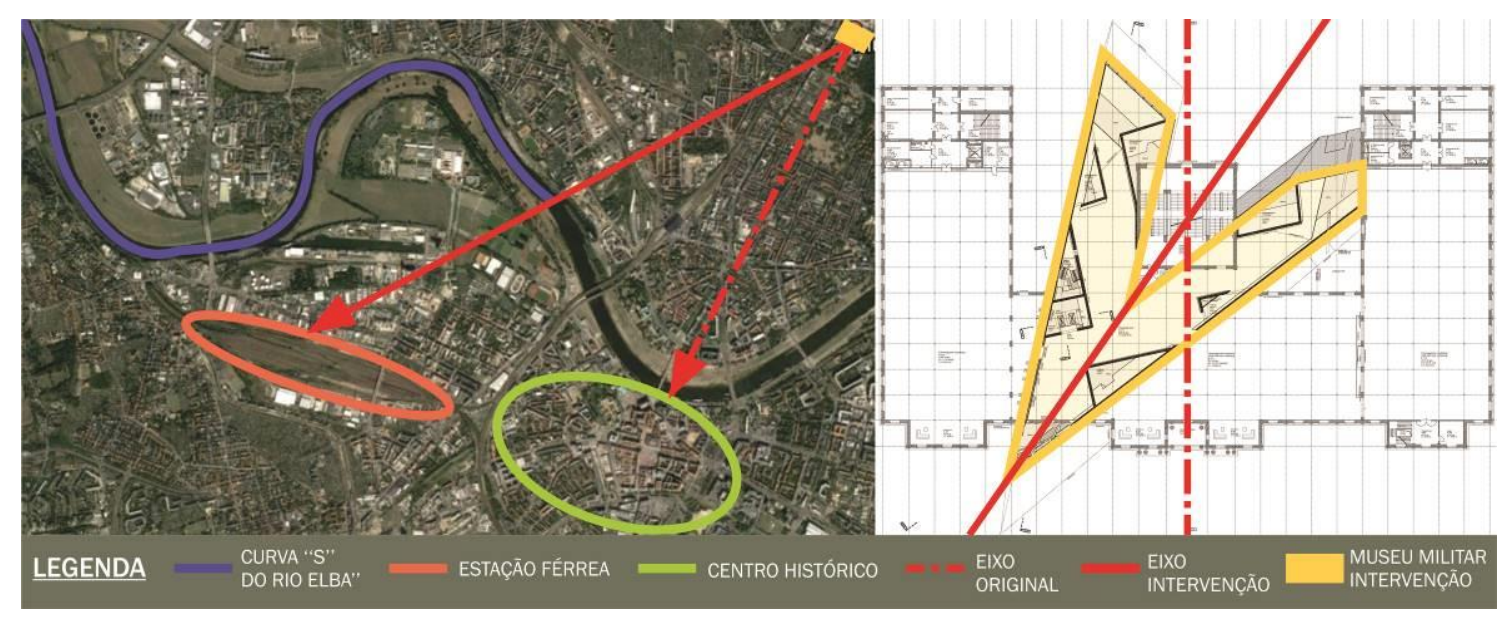

Figura 1 - Relação do eixo da intervenção em planta baixa com o entorno

Fonte: adaptado de Google Maps e www.libeskind.com 
Analisando a fachada (Figura 02), é possível visualizar a segregação da intervenção (2) sobre o edifício original (1), o que evidencia a intenção projetual de justaposição entre o novo e o velho. Esse efeito é facilitado pelo contraste de materiais e texturas, bem como pela quebra da simetria neoclássica, adicionando uma pirâmide inclinada que perfura a preexistência, uma possível conexão com o inconsciente coletivo sobre um ícone de museu, - Louvre. Desta maneira, já provocando uma instabilidade, um estímulo à reflexão sobre o tipo de intervenção direcionada à mudança de perspectiva do Museu, especialmente sobre a "cultura da violência".

Além disso, é possível identificar relações geométricas bem definidas entre os elementos compositivos da preexistência com os da intervenção. O diagrama da Figura 2, elaborado sobre a imagem da fachada principal do Museu destaca algumas destas relações. Observa-se a lógica de caracterizar, sob este ponto de vista, o contorno aparente da intervenção como um triângulo cujo um dos lados se posiciona perpendicular ao lado de um triângulo equilátero, com eixo comum à simetria da preexistência.

A malha ortogonal, que estrutura os panos de vidro, conforme indicado na mesma figura, no sentido (A) tem direção paralela a um dos lados do triângulo que define a forma dos frontões que estão posicionados acima das janelas. No sentido (B), tem direção bastante próxima à da diagonal das janelas. Com esta estratégia, estabelece uma razão entre as partes, tratando de seguir a lógica de comensurabilidade e lograr uma harmonia compositiva.

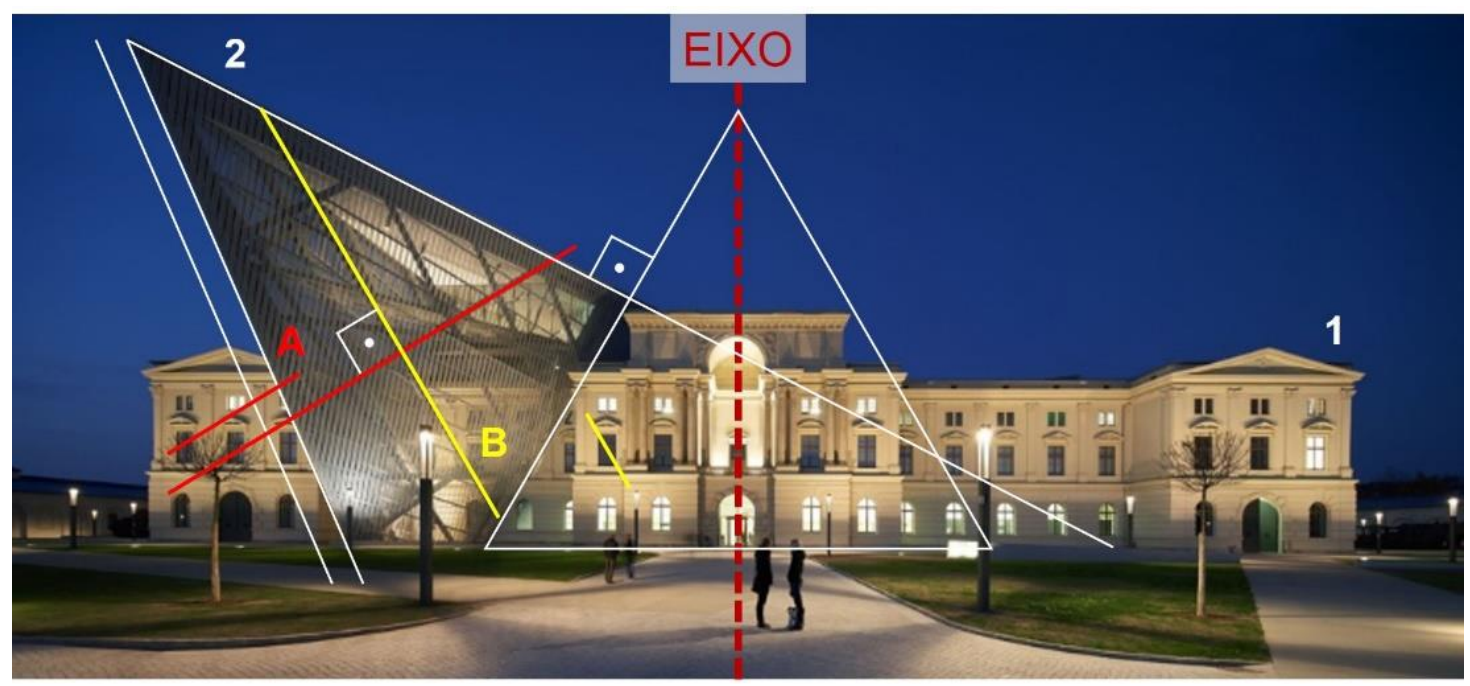

Figura 2 - Análise da fachada quanto a quebra da simetria e equilíbrio em relação ao eixo original

Fonte: adaptado de www.libeskind.com

Com a Figura 3 registra-se o exercício de análise do efeito de figura/fundo. pois o edifício original tem feitio de um quadrilátero retangular, enquanto a intervenção, de um polígono piramidal. O que também corrobora para isso é o contraste provocado entre a horizontalidade do antigo e a verticalidade do novo. Tais estratégias vão ao encontro da intenção projetual de promover uma "justaposição de tradição e inovação".

Também é possível visualizar que, apesar dos efeitos já encontrados até o momento, tais como, segregação, contraste e desequilíbrio, o todo da fachada apresenta harmonia, possivelmente estabelecida a partir da 
utilização do enquadramento da intervenção inserida em um quadrado, o que também é percebido nos elementos principais da fachada original.

Observa-se, (à direita da figura3), que em vista frontal a intervenção está delimitada por um triângulo que parece derivar de um jogo geométrico realizado entre um quadrado e um retângulo de proporção raiz de 2: a hipotenusa deste triângulo é o lado de um quadrado, definindo dois vértice, sendo que o terceiro vértice é o centro do retângulo, cujo lado maior é o lado do mesmo quadrado.

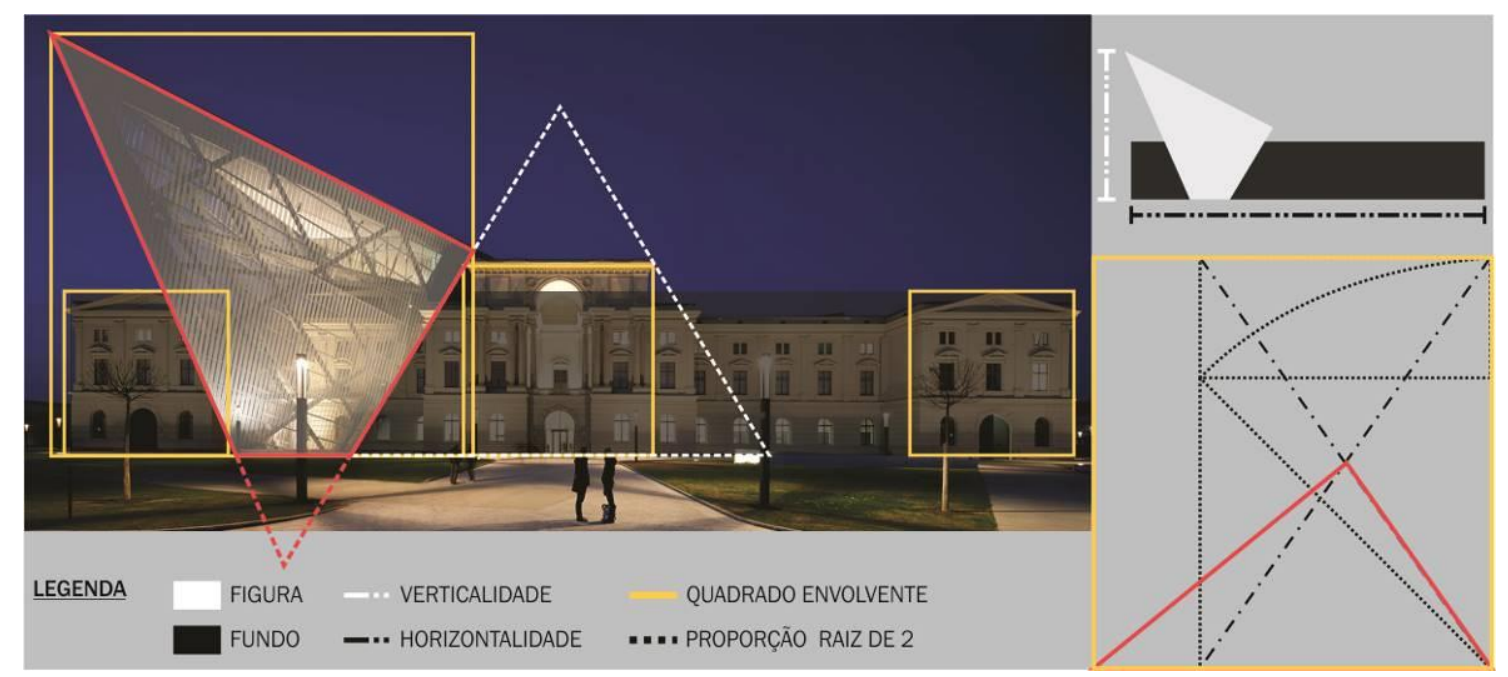

Figura 3 - Esquema da fachada quanto a figura/ fundo e proporção

Fonte: adaptado de www.libeskind.com

A intervenção desequilibra o todo, convida à reflexão sobre a necessidade de romper com o passado sem negá-lo e escondê-lo, podendo ser identificada como instrumento para a experimentação sensorial do usuário e sua reflexão do passado, presente e futuro, contribuindo ainda, à noção de tempo e espaço. Assim, tanto o arquiteto, quanto a obra chamam a atenção pelo discurso engajado em um ideal e por suas formas e texturas que tornam o exemplar arquitetônico uma imagem ressonante, capaz de contar uma história através das estratégias projetuais.

\section{RESULTADOS E DISCUSSÃO}

A partir do discurso do arquiteto e em declarações de críticos e pessoas envolvidas no processo de execução da intervenção foi possível identificar um conceito como fio condutor para intenções projetuais. Observa-se que o conceito utilizado é o de ressurreição no pós-guerra, no qual aborda os impactos causados e como a sociedade se reconstroem.

Para tal, buscou no contexto subsídios para entender quais foram esses impactos, em especial o bombardeio que destruiu a cidade de Dresden, o que interferiu diretamente nas intenções e estratégias projetuais de estabelecer relações entre a obra e o entorno e entre o observador e a obra.

A análise geométrica da imagem se mostrou um exercício provocativo para reflexões, interpretações e observações das estratégias projetuais, principalmente ao buscar relacioná-las com as lógicas perceptivas da Gestalt, 
quais sejam, pregnância, segregação, contraste, simplicidade, clareza, figura/fundo e desequilíbrio.

O exercício permitiu assim estabelecer relações entre o conceito, a Gestalt e a geometria. Buscou-se assim interpretar a organização formal como os movimentos de rotação do eixo do volume principal da intervenção em relação ao da preexistência, como a estratégia de assimetria desta intervenção em relação ao todo.

Ao mesmo tempo, compreender as relações de perpendicularidade, paralelismo, permanência de proporções entre os dois projetos, o uso de figuras e proporções recorrentes na arquitetura, tanto enquanto figuras planas (triângulos equiláteros e retângulos raiz de 2), quanto como figura tridimensional: pirâmide inclinada, fazendo associação à imagem de um Museu (Louvre de Paris).

A pesquisa não se propôs a discutir outros aspectos da Gestalt e da forma como cor, textura, movimentos, e tridimensionalidades, por se tratar da análise de uma imagem estática, que representa e bidimensionalidade da obra, mas se propôs a problematizar a importância da análise para adquirir repertório formal, repertório de intencionalidades e de conceito.

\section{CONCLUSÕES}

Sem dúvidas após o evento da tempestade de fogo a cidade de Dresden passou a ser um símbolo dos efeitos de uma guerra. No âmbito dessas questões sociais e humanas atreladas à temática da função simbólica da arquitetura o arquiteto Daniel Libeskind cria uma intervenção contemporânea em um edifício neoclássico para reabrigar o Museu de História Militar Alemã, com a intenção de falar sobre a guerra demonstrando como ela pode devastar uma cidade e ainda propondo novas perspectivas sobre o tema.

Através do exercício foi possível exemplificar, com os elementos da geometria, as estratégias do arquiteto quando quis dar contraste para expressar a justaposição entre o novo e o velho. Quando manteve a harmonia para expressar como a violência organizada e como a história militar e o destino da cidade estão interligados. Como a rotação do eixo principal da intervenção em relação à preexistência direciona o olhar do expectador para o cenário que quer contrastar, isto é, a estação férrea, alvo inicial dos ataques a Dresden.

Observou-se a principal lei da Gestalt, a pregnância, apoiada na segregação, figura/fundo e em efeitos como simplicidade, clareza e instabilidade para criar uma forma que penetra na preexistência, com o intuito de preservar a memória para que nunca mais aconteça.

Ademais, a clareza destas estratégias projetuais, corrobora na investigação acerca da transposição do conceito, no que tange às necessidades simbólicas, para a concepção formal, aplicando assim a teoria da Gestalt como lógica para o processo projetual. 


\section{REFERÊNCIAS}

BRANDÃO, Carlos Antônio Leite. Linguagem e arquitetura: o problema do conceito. Revista de Teoria e História da Arquitetura e do Urbanismo. vol.1, n.1, novembro de 2000. Belo Horizonte: Grupo de Pesquisa "Hermenêutica e Arquitetura" da Escola de Arquitetura da UFMG. Acesso em: 07 Set. 2018. Disponível em: <https://arq1 103.files.wordpress.com/2012/02/arq1 103_exl_linguagem-earquitetura-o-problema-do-conceito.doc.>;

FLUSSER, Vilém. Filosofia da caixa preta: ensaios para uma futura filosofia da fotografia. $-1^{a}$ ed. - São Paulo: Annablume, 2011;

FONATTI, Franco. Principios elementales de la formaen arquitectura. - $4^{a}$ ed. Barcelona: Gustavo Gili, 1988;

IRVING, David. A Destruição de Dresden: A Anatomia de uma Tragédia. Nova Fronteira, 1963.

KASISKE, Andrea. Museu em Dresden resgata história militar alemã. In: Deutsche Welle Brasil. Publicado em 2013. Acesso em: 20 Mai. 2019. Disponível em: https://www.dw.com/pt-br/museu-em-dresden-resgata-hist\%C3\%B3riamilitar-alem\%C3\%A3/a-16765090

KÖHLER, Wolfgang. Psicologia da Gestalt; tradução: David Jardim. - $2^{a}$ ed. Belo Horizonte: Itatiaia, 1980;

LIBESKIND, Daniel. Military History Museum, Dresden, Germany. Disponível em: <https://libeskind.com/work/military-history-museum/>. Acesso em: 09 Nov. 2017;

MOORE, Rowan. Military History Museum - review. The Guardian. Publicado em 23 Out. 2011. Acesso em: 07 Set. 2018. Disponível em: <https://www.theguardian.com/culture/201 1/oct/23/military-history-museumdresden-review>;

REDAÇÃO DE AU. Arquitetura brasileira tem espaço internacional: Daniel Libeskind não vê tecnologia como empecilho para arquitetos brasileiros. In: Revista AU. Publicado em 23 Mar. 2009. Acesso em: 09 Nov. 2017. Disponível em: <piniweb.pini.com.br/construcao/arquitetura/daniel-libeskind-arquiteturae-comunicacao-129337-1.aspx>;

STROETER, João Rodolfo. Arquitetura e Teorias. - São Paulo: Nobel, 1986;

SEVERINO, Antônio Joaquim. Metodologia do trabalho científico. $-24^{a}$ ed. - São Paulo: Cortez, 2016;

Texto fornecido pelo Studio Daniel Libeskind. Dresden's Military History Museum / Studio Libeskind. Publicado em 14 de outubro de 2011. Acesso em: 20 Mai. $2019 . \quad$ Disponível em: https://www.archdaily.com/172407/dresden\%25e2\%2580\%2599s-military-historymuseum-daniel-libeskind

THORNS, Ella. Museu Militar de Daniel Libeskind, pelas lentes de Alexandra Timpau. Publicado em 16 Novembro, 2017. Acesso em: 20 Mai. 2019. Disponível em: https://www.archdaily.com.br/br/883528/museu-militar-de-daniel-libeskindpelas-lentes-de-alexandra-timpau;

WONG. Wucius. Princípios de forma e desenho. 5a. Ed. São Paulo: Martins Fontes, 2007. 